\title{
NOTICIAS SOBRE LA ACADEMIA DE BELLAS ARTES.DE SAN CARLOS
}

$\mathbf{P} \bigcirc \mathbf{R}$

\section{A R TURO AR N A I Z Y F R E G}

F L “Ensayo Político Sobre el Reino de la Nueva España”, dió a conocer Iun país oculto al mundo por el celo de sus dueños. Todo cuanto de valioso encerraba esta colonia, fué encarecido y elogiado con largueza por el Barón de Humboldt. Su libro impuso en México al viajero inteligente un itinerario.

La Academia de Bellas Artes de San Carlos fue, sin duda, una de las instituciones que más interesaron al poligrafo prusiano: "la Academia trabaja con fruto", escribió. Vivía el establecimiento en 1803 sus mejores días.

Más tarde, fueron numerosos los hombres de estudio que se internaron en nuestro. país aprovechando las facilidades que otorgó el Gobierno independiente. Sus relatos, a veces breves $e$ inexpresivos, tienen con frecuencia un inconfundible acento justiciero.

Afluyeron los viajeros y la Academia, polsre ya, continuó siendo lugar de tránsito obligado. Abandonada a su suerte, estuvo a punto de extinguirse. En 1845, la oposición entre su lamentable estado y la brillante descripción de Humboldt era tan grande, que Waddy Thompson no vaciló en atribuír los elogios del sabio a la impresión que en su ánimo hiciera la Güera Rolríguez.

A pesar de sus contradicciones, los juicios de los visitantes nos pernuiten seguir de cerca la historia de la institución. 
Deseosos de cumplir con uno de los propósitos del Instituto de Investigaciones Estéticas, hemos recogido los testimonios sobre el estado de la Academia de San Carlos, que nos ha sido dable encontrar, para que, unidos a los frutos de la investigación documental, faciliten a los estudiosos la elaboración de la visión integra donde aparezcan los hechos en su verdadera perspectiva. 
11 de nuviembre de 1789

Carta Reservada del Excmo. Sr. Virrey Conde de Revilla Gigedo al Excmo. Sr. D. Antonio Porlier.

Excmo. Sr.- Procurando yo enterarme a fondo de quantos establecimientos útiles hay en el Reyno y particularmente en esta ciudad, he hallado que en la Academia de las Tres Nobles Artes establecida en ella con el nombr de Sn. Carlos se adelanta poco o nada, ya sea por la desidia de los discípulos, ya por la falta de principios sólidos y científicos, o ya por la poca asistencia, mal método y morosidad de los mismos Directores. 1

Pensando yo pues el modo de hacer prosperar un establecimiento tan útil a este Reyno, y que dará esplendor a la Nación si llega a perfeccionarse, creo conveniente que en adelante no se enseñe en dicha Academia más que la Arismética, Geometría y demás partes de la Matemática auxiliares de las bellas Artes: La osteologia, la Mitología, las proporciones del cuerpo humano,-el antiguo por los buenos huesos que se han pedido, y el natural por el Modelo vivo-, y que en haviendo pasado estas clases con aprovechamiento, se obligase o inclinase a los Pensionados o discípulos de conducta y más talento a que pasasen a España a aprender la Pintura, la Escultura, la Arquitectura y el Gravado en Lámina con los profesores de más fama de la Corte, distribuyendo en esto seis mil pesos anuales de los diez mil que en el día se gastan con los cinco Directores; pero siempre era mentester uno de pintura

1 El propio Revillagigedo asienta en su Instracción Reservada: "El establecimiento de la real academia de nobles artes de San Carlos, ba proporcionado muchas ventajas en esta parte"."

"Se halla actualmente provista de muy buenos profesores, así en arquitectura como en pintura, escultura y gravado".

"Institución Reservada que el Conde de Revilla Gigedo, dió a su sucesor en el mando Marqués de Branciforte sobre el Gobierno de este Continente en el Tiempo que fué so virrey."-México-_ 1831 .-Pág. 85.-Párrafo 342. 
y aún el de Arquitectura hasta que bolbiesen los que fuesen en disposición de poder enseñar por afición y por naturales del País con una corta gratificación, como se hace en la Academia de San Fernando de Madrid.

En esta Casa de Moneda ha de haver siempre un Gravador mayor célebre en su arte por lo mucho que importa y por su buena dotación. El actual goza sobre su sueldo la ayuda de siete mil pesos por enseñar a varios pensionados y otros que se apliquen para repartirlos oportunamente en las Casas de Moneda de Indias, y por Real Orden de 12 cle Abril de 1786, la de 500 pesos sobre los Fondos de la Academia como Director particular del Gravado de Medallas por gracia particular y debiendo servir este entpleo los que le sucedan sin otra asignación que la primera, se debe suponer que en esta parte tendrá siempre un buen Maestro la Academia sin gravamen propio.

Esta es la nueva forma que me parece dar a la Acadenia, y la manifiesto a $\mathrm{V}, \mathrm{E}$. para que si fuese del mismo parecer, y llegase a tiempo esta representación se sirva suspender la provisión de la Dirección vacante de escultura, hasta tanto que tratándose eił Junta este pensamiento conforme previene el Cap. 13 artículo 32 de los estatutos, como tamvién el modo de evitar los dos únicos obstáculos que se me ofrecen en quanto a lo que deva hacerse con estos Directores que parecería rigor despojarlos de sus empleos sin culpa suya; y sobre la preferencia con que por un amor desordenado a su Patria y a su Gente miran estos Naturales y aún los mismos que andan desnudos, su condición, tal qual fuese, a qualquiera buen partido y esperanza se informe a S. M. en cumplimiento del Capítulo 10.-Artículo 10 de los citados Estatutos, de lo que se crea más acertado, remitiendo un nuevo plan de formación fundaclo en estos principios que contribuya a los mejores progresos de la Academia.

Dios guarcle a V. E. muchos años.-México.-11 de Noviembre de 1789.

$$
\text { Revilla Gigedo. (Rúbrica). }
$$

Excmo. Sr. Dn. Antonio Porlier.

Manuscrito perteneciente al Archivo General de la Nación, donde ha sido descubierto por A. Arnáiz y Freg, en el Tomo 30 de la Sección de Correspondencia de Virreyes: "Minutas de Cartas dirigidas a España por la Secretaria Particular del Excmo. Señor Conde de Revilla Gigedo en la clase de reservadas que me entregó su E,xa. en distintas ocasiones y la mayor parte mui pocos días antes de entregar el Virreynato.-Se arreglaron en el mes de Julio de 1794". - Antonio Bonilla. (Rúbrica), - La carta, - foja 162- 
lleva al margen una anotación manusrrita que textualmente dice: "El Virrey" de N. E., Conde de Revilla Gigedo da cuenta del mal estado en que se halla la Academia de las Tres Nobles Artes de esta ciudad, proponiendo los medios que le parecen adecuados para su restablecimiento.-(Contestada en Real Orden de 3 de marzo de 1790).

"Se ha establecido una Acadenia de las tres nobles artes con el titulo -le San Carlos, cuyo Vice-Protector es el señor Virrey: compónese de gran uúmero de Consiliarios, de Acaclémicos de honor, y de Directores particulares: dos de pintura, uno de escultura, otro de arquitectura, otro de grabado en lámina, con un Catedrático de Matemáticas y dos Tenientes Directores de pintura y escultura. Esta Real Academia mantiene diez y seis pensionados, quatro de ellos indios puros. con quatro reales diarios: quatro en la pintura, quatro en la escultura, quatro en la arquitectura, dos en el grabado en hueco y dos en el grabado en lámina. Tolos los meses se distribuyen en varios premios sesenta y seis pesos entre los discipulos que presentan mejores obras y dibujos, calificándose antes en la junta ordinaria".

De la obra: "El Viagero Lniversal o noticia del Mundo Antiguo y' Nuevo". Obra Recopilada de los Mejores Viageros por D. P. E. P. Tomo XXVI. Madricl. 1799. (Cuarlerno Setenta y Ocho. Carta DIII. "Idea General de México. Continuación del Mísmo Asunto". Págs. 354-355.

"Ninguna ciudad del nuevo continente, sin exceptuar las de los Fistados Unidos, presenta establecimientos cientificos tan grandes y sólidos como la capital de México. Citaré sólo la escuela de minas dirigida por el sabio Elhúyar, y de la cual hablaré cuando trate del beneficio de los metales : el jardín botánico, y la academia de pintura y escultura conocida con el nombre de "Academia de las nobles artes". Esta academia debe su existencia al patriotismo de varios particulares mexicanos, y a la protección del ministro Gálvez. El gobierno le ha cedido una casa espaciosa. en la cual se halla una colección de yesos más bella y completa que ninguna de las de Alemania. Se adnira uno al ver que el Apolo de Belveder, el grupo de Laocoonte, y otras estatuas 
aún más colosales, han pasado por caminos de montaña que por lo menos son tan estrechos como los de San Gotardo; y se sorprende al encontrar estas grandes obras de la antigüedad reunidas bajo la zona tórrida y en un llano o mesa que está a mayor altura que el convento del gran San Bernardo. La colección de yesos puesta en México ha costado al rey cerca de 40,000 pesos. En el edificio de la Academia, o más bien en uno de sus patios, deberían reunirse los restos de la escultura mexicana, y algunas estatuas colosales que hay de basalto y de pórfido, cargadas de jeroglíficos aztecas, y que presentan ciertas analogias con el estilo egipcio e hindú. Seria ana cosa muy curiosa colocar estos. monumentos de los primeros progresos intelectuales de nuestra especie, estas obras de un pueblo semi-bárbaro, habitante de los Andes mexicanos, al lado de las bellas formas nacidas bajo el cielo de la Grecia y de la Italia.

"Las rentas de la Academia de las Bellas Artes de México son de 24,500 pesos, de los que el gobierno da 12,000, el cuerpo de mineros mexicanos cerca de 5,$000 ;$ y el consulado más de 3,000. No se puede negar el influjo que ha tenido este establecimiento en formar el gusto de la nación; haciéndose esto visible más principalmente en la regularidad de los edificios y en la perfección con que se cortan y labran las piedras, en los ornatos de los capiteles y en los relieves de estuco. Son muchos los buenos edificios que ya en el día hay en México y aún en las ciudades de provincia, como Guanajuato y Querétaro. Son monumentos que a veces cuestan 300,000 pesos, y que podrían figurar muy bien en las calles de Paris, Berlin y Petersburgo. El señor Tolsa, escultor de México, ha llegado a fundir allí mismo una estatua ecuestre de Carlos IV; y es obra que, exceptuando el Marco Aurelio de Roma, excede en primor y pureza de estilo cuanto nos ha quedado de este género en Europa. La enseñanza que se da en la Academia es gratuita, y no se limita aI dibujo del paisaje y figura ; habiéndose tenido la buena idea de emplear otros: medios a fin de vivificar la industria nacional, la academia trabaja con frutoen propagar entre los artistas el gusto de la elegancia y belleza de las formas. Todas las noches se reunen en grandes salas, muy bien iluminadas con argand, centenares de jóvenes, de los cuales unos dibujan al yeso o al natural, mientras que otros copian diseños de muebles, candelabros u otros adornos de bronce. En esta reunión (cosa bien notable en un país en que tan inveteradas son las preocupaciones de la nobleza contra las castas), se hallan confundidas las clases, los colores y razas; alli se ve el indio o mestizo al lado del blanco, el hijo del pobre artesano entrando en concurrencia con los de los. principales señores del país. Consuela ciertamente el observar que bajo todas las zonas el cultivo de las ciencias y artes establece una cierta igualdad: 
entre los hoinbres y les hace olvidar, a lo menos por algún tiempo, esas miserables pasiones que tantas trabas ponen a la felicidad social".

De la obra: "Ensayo Político Sobre el Reino de la Nueva España", por Alejandro de Humboldt.--Tomo I.-Libro II.-Capitulo VII.- (Se ha utilizado la traducción española de D. Vicente González Arnao, publicada en París, en Casa de Rosa en 1822).

5 de noviembre de 1822

"Temprano, en la mañana, visitamos la Academia de Bellas Artes, que fue una escuela dé pintura y escultura, pero que hoy está olvidada y convirtiéndose en ruinas por las mismas causas que han dañado a otras instituciones: los fondos han sido destinados a otros usos, debido a las exigencias del gobierno.

"Hay una muy buena colección de vaciados en excelente estado de conservación, pero quién sabe el tiempo que duren asi, porque parte del techo se ha derrumbado cerca de ellos, y el agua cae en el piso de la sala en que se encuentran.

"El vaciado de Laocoonte es uno de los mejores que he visto. Hay algunas pinturas-ninguna de ellas muy buena--esparcidas a lo largo de las paredes, y vimos una gran fila de bancas y escritorios con dibujos y modelos para los alumnos, como si los hubiesen dejado ayer, siendo así que no se ha dado ninguna lección desde hace más de doce meses. Hay también una sala para modelado y dibujo al natural, y toda clase de comodidades para el estudiante de las bellas artes".

De la obra "Notes in Mexico, made in the Autumn of 1828 ". By a Citizen of the United States. (Joel R. Poinsset). Filadelfia. 1824. Págs. 71-72.

\section{9 a 10 de noviembre de 1822}

"Futimos a vagar una vez más a la Academia de Bellas Artes. Hay una buena pintura de Fernando VII que ha sido arrumbada en una pequeña alacena. La colección de vaciados es ciertamente muy buena. Es indudable que esta institución ha producido amor por las bellas artes $\mathrm{y}$ ha refinado el gusto de las gentes, pero no pienso que se hayan formado en ella buenos artistas. 
Todas las pinturas modernas que he visto no son sino monos. Los retratos de Iturbide, que se supone fueron pintados por el mejor artista, son pésimas muestras de la condición de las artes aquí".

De la obra "Notes in Mexico, made in the Autumn of 1828 ". By a Citizen of the United States. (Joel R. Poinsett). Filadelfia. 1824. Pág. 118.

"La Academia de Bellas Artes ha sido extinguida por la revolución: al presente no tiene ni estudiantes ni director. El edificio y los vaciados de yeso subsisten aún, pero sus fondos se han perdido, epodremos esperar su restauración?

"El Batón de Humboldt nos ha hecho una descripción, más bien lisonjera del establecimiento en la época en que visitó el país. Si su información fué correcta,- como, en efecto, tengo todas las razones para creerlo,--veinte años de guerra interna e insurrecciones han producido un cambio deplorable en el estado de las Artes.

"Al presente no hay un solo alumno en la Academia, y aunque st venerable Presidente vive todavía, está en la miseria y casi ciego.

"Ni un paisajista, ni un pintor de monumentos arquitectónicos queda en esta gran ciudad, sus únicos artistas son los que copian asuntos religiosos para los templos o aquellos que intentan retratar; pero todos son rieplorablemente malos. Parece que el empleo principal del lápiz es el de decorar carruajes y cabeceras de camas de madera. En las capitales, algunos cuadros del Niño Jesús, de la Virgen, de la Magdalena, de San Antonio o de San Cutberto,- únicas producciones de los pintores modernos, - llenan iglesias, conventos, claustros, etc. Vi muy pocos que no merezcan ser quitados. Las iglesias y catedrales pueden tener algunos buenos entre los muchos de que están repletas, y supongo que los tendrán; pero la cantidad de luz que penetra en tan soberbios templos es, aun en los días más luminosos, muy limitada para poder descubrir el mérito que tienen: perdidos están para el mundo en ja sagrada penumbra que envuelve estos lugares. Asimismo, el público no puede acércarse a ellos, debido a unos velos antiestéticos; pero por lo poco que logré ver, atisbando a través de estas barreras, me pareció que podrian estar aquí, enterradas en el olvido, algunas de las mejores producciones de las escuelas Italiana y Española. 
"Visité las casas de muchas personas de la nobleza; pero encontré en ellas muy poco que sea digno de referirse. La galería de dibujos del Conde de la Valenciana tiene un juego de grabados de Claud, que, con algunas cosas buenas que hay en el palacio del Obispo de Puebla, son los. únicos trabajos que merecen mencionarse en conexión con los antiguos maestros.

"En mis andanzas por la ciudad, visité a menudo las mueblerias y los bazares, pues entre el incontable número de estatuas y pinturas de santos y de mártires, esperaba hallar algo que valiera la pena de traer a mi casa; pero todas mis búsquedas en este sentido sólo me produjeron dos pequeñas pinturas, una en cobre,- La Adoración de los Pastores,- de los primeros trabajos o copia de Coreggio, y una Sagrada Familia que tiene algo del estilo de Carlo Maratti.

"Me habia imaginado que la sorprendente y rápida acumulación de la riqueza adquirida por varios individuos en el trabajo de las minas de plata, habría ocasionado, por devoción o por buen gusto, el que algunas producciones del arte europeo hubiesen cruzado el Atlántico; pero no parece que tal cosa haya acontecido. Si asi fue, acompañaron a los españoles en stu retirada a la madre patria.

"No vi huellas de la ocupación del escultor en mármol: esto puede explicarse por las costumbres del país, que prohiben el uso de monumentos. Tampoco hay hogares que admitan ornamentación de chimenea. Hay muchos tallistas en madera, ya que cada casa tiene un estatua de algún santo o Madona pintada $\mathrm{y}$, casi siempre, vestida magnificanente. El arte del grabado en piedra es desconocido en México, pero los indios sobresalen grandemente en el modelado y en los trabajos en cera. Los ejemplares de diferentes tribus y de las costumbres y vestidos de la gente distinguida del país que he traído (a Londres), probarán ampliamente sus méritos en esta rama del Arte; modelan también legumbres y frutas de un modo admirable. Una dama de Puebla ejecuta en un estilo singular grupos de figuras cómicas con piezas de paño antiguo, de los cuales he traído a Inglaterra algunos. Tal era su habilidad, que habiéndome mirado sólo unos momentos cuando pasé la primera vez por aquella ciudad, al volver me sorprendió hallarme con que había hecho mi retrato en este estilo y, por su notable parecido, fue reconocido en el acto por mis amigos".

De la obra: "Six Months Residence and Travels in Mexico", by W. Bullock, fellow of the Linnean, Horticultural, Geological and other Societies.-Londres,-1824.-Capítulo XI.-Tomo I. Págs. 165-168. 
"Ciertamente, la parte más desagradable de México, a fines de 1823, era su población de mendigos que convertía los suburbios en un espectáculo de inmundicia y miseria continuo. Veinte mil de estos "léperos" infestaban en aquel tiempo las calles, exhibiendo un cuadro de infelicidad tal, que no hay palabras para definirlo convenientemente. Siendo ya extraordinaria la fealdad natural de los indígenas-particularmente en los viejos-?, haciase lo posible por aumentarla con la mezcla repugränte de mugre y harapos. No tenian vestidos: el hombre llevaba una manta llena de agujeros y la mujer unas enaguas andrajosas, esto era para ambos el mayor adorno. La exhibición de sus cuerpos, consecuencia natural de la falta de ropa, era verdaderamente intolerable para el extranjero. Sin embargo, entre estas criaturas degeneradas se encuentran individuos dotados de facultades naturales que, guiados convenientemente, harán que muy pronto cambie su situación. Las figuras de cera de la exhibición de Bullock, conocidas por la mayoría de los habitantes de Londres, están todas hechas por los léperos con los instrumentos más toscos. Algunas están bellamente acabadas, particularmente las imágenes de la Virgen, pues muchas tienen una dulce expresión de bondad que debe haber sido copiada originalmente de alguna pintura de Murillo, pues es dificil suponer que los hombres que las hacen, hayan podido imaginarse alguna vez un rostro así. Creo que es Humboldt el que dice que los hombres de rostro cobrizo sólo emplean sus facultarles en la imitación: en esto seguramente no tienen rival, pues durante el tiempo que ha estado abierta la Academia de San Carlos,-institución liberal en la que la etseñanza del dibujo y del nodelado se impartía con todos los útiles necesarios costeados por el tesoro nacional,--algunos de los alumnos que más prometían, surgían de entre los indios menos civilizados de la población. Parecían dibujar por instinto, diré, para emplear las mismas frases del profesor que dirigía el establecimiento, y copiar con la mayor facilidad cuanto se les pusiera enfrente. Pero no son constantes. Pronto se aburren de las pequeñas restricciones que impone el reglaménto, y después de tomar algunas lecciones, desaparecen para no volver jamás. Falta saber si algo puede hacerse por medio de un mejor sistema de gobierno, en beneficio de una raza compuesta de elementos tan heterogéneos. En 1824 no eran los indios sino un estorbo público. Apenas si era posible transitar por las partes de la ciudad habitadas por ellos, y a no ser por la extrema pureza del aire, la mugre acumulada frente a las puertas de sus casas hubiera causado una epidemia". 
De la obra: "Mexico in 1827". By H. G. Ward. (His Majesty's Chargé $D^{\prime}$ Affaires in that country during the years 1825, 1826 and Part of 1827.-Londres.-1828.-Libro V. - Sección II.-Págs. 236-238 del Segundo Tomo).

El primer artista europeo que ilustró a México después de la Conquista, el primero al menos que he podido encontrar en mis búsquedas, fué un tal Arteaga. Un cuadro, La Visitación de la Virgen, en Santa Teresa la Antigua, revela que su pincel tuvo el estilo elevado, expresivo y patético que distinguía entonces a la escuela española. Era también arquitecto, y acaso a él se deben una parte de los bellos edificios de la ciudad. Se supone que un indio llamado Telpochtepico, a quien se cree autor de mis catorce cuadros cronológicos, estudió con él e hizo grandes progresos. Eira un indio de Michoacán, el Atica del México Antiguo. 1

1 Comentando este relato de Bejtrami, don José Bernardo Couto dice en su "Diálogo sobre Ja Historia de la Pintura en México".-México.—1872. -Págs. 14 a 16 :

\section{"CLAVE}

'Yo he leido en el viaje del italiano Beltrami, que estuvo acá por los años de 24 y 25, que el primer pintor europeo que ilustró a México después de la conquista. fué un tal Arteaga, y que tras él vino Cristóval de Villalando: y dice que del primero vió una Visitación de la. Virgen en Santa Teresa la Antigua, y del segundo soberbias pinturas en San Francisco y San Agustín.

\section{“COUTO}

"No son esas las únicas ni quizá las mayores equivocaciones del viajero piamontés. El pintor Arteaga que conocemos en México, es Sebastián de Arteaga, de quien hay en esta sala ese excelente cuadro del Desposorio de ja Virgen, estimado por Vdes. como una de nuestras mejotes joyas. Pero le recuerdo, que en una imagen de Cristo crucificado, que juntos examinamos vd. y yo en la sacristia de la Colegiata de Guadalupe, hace ya algún tiempo, lémos que había sido hecha por Sebastián de Arteaga el año de 1642 . No pudo. pues, ser el primer pintor europeo venido a Nueva España. Respecto del segundo, supongo que Beltrami quiso referirse a Cristóbal Villalpando, de quien hay porción de pinturas en la ciudad. Pero por los cuadros de la Pasión, que están en los corredorea altos de San Francisco. y (entre nosotros sea dicho) nada tienen de soberbio, consta que pintaba en 1710 . No es, pues, el segundo en el orden cronológico de nuestros pintores A Beltrami debemos estar agradecidos por la estima que hizo de nuestra escuela de pintura, y porque lejos de dejarse llevar, con respecto a ella. del espíritu de murmuración que sobre todas materias es tan común en los viajeros que nos visitan, más bien haya pecado de largo y fácil en elogios. Pero no puede ponerse gran confianza en sus noticias, porque generalmente son inexactas. 
Cristóbal Villalpando viło después, era igualmente pintor y arquitecto. Soberbios pinturas de él se ven en San Agustín y en San Francisco; si realmente el dibujo de la iglesia de S. Agustín es obra suya, es. sin duda el Paladio de su nación. A mi nodo de ver es éste el edificio más atrevido y majestuoso que hay en México. Ha pintado en Celaya, Querétaro y otros lugares. En todas partes su pincel ha estado admirable.

El Reverendo Padre Prior de los Agustinos me ha mostrado un cuadro en madera al que dejan devorar por el polvo en un cortedor del convento. E1 lo atribuye a Villaipando sin dudar que podria ser una de las más bellas obras de Murillo. Ess un San Pedro que se arrepiente de haber negado tres veces a Nuestro Señor. Se ve la rudeza y la debilidad de un humilde pescador, el arrepentimiento humano unido a una divina esperanza que esparce sobre su rostro la gracia, anuncio del Espíritu Santo que debe residir en él. La figura del gallo expresa todos los reproches amargos que le taladran el corazón $y$ su canto es indignado y penetrante. La soledad de la escena es la más conmovedora; uno se entrega a la más. profuncla contemplación bajo los árboles frondosos, entre antros y rocas. Lo romántico, lo sublime, lo terrestre y lo celeste, todo está pintado de la manera más sorprendente $y$ el tema recuerda con la más ingenua expresión a muchos otros apóstoles que niegan todos los dias, por sus acciones reprobalsles, a este Divino Redentor que ofrecen sin cesar a los demás, con voces hipócritas, como modelo digno de ser imitado. Si alguno de nuestros annigos viene a México, que no deje de ver esta obra maestra de arte, en el supuesto de que la encuentre todavía, pues habiendo ido a admirarla con frecuencia, creo haber aumentado un poco más su valor a los ojos de los reverendos padres, que cederán, por consiguiente, a la tentación de hacerla desaparecer.

El tercer artista español fué Baltasar Chaves. Ha dejado en la Profesa cuadros muy hermosos, en los que se advierte mucho de la manera de Guercino.

En el siglo XVII hubo un gran número de artistas mexicanos, la mayor parte alumnos de esos tres pintores. Los más ilustres fueron $M a$ nuel Arellano, Antonio Aquilera, Josí Torres, Clemente López, Andrés López y Herrera, llamado El Dirrîho porque pintaba divinamente. Los dos cuadros suyos que he visto, uno en la Catedral y otro en la Iglesia de Jesús María, justifican el epíteto que le honra. El cuadro de Nuestra Señora de Guadalupe, de Aquilera, que se enctentra en la Iglesia de la Encarnación, revela una gran maestría en el dibujo y en los colores; y los cua- 
dros de Torres, del Palacio de la Inquisición, muestran un pincel atrevido, aunque un poco amanerado.

El siglo XVIII fué para México el siglo de León X; brillaron entonces artistas cuyas obras serian ornato de las mejores galerias de En1ropa. Los tres Rodríguez, Luis, Juan y Nicolás, florecieron al principio de este siglo. Las obras de $J_{u a n}$, en la Catedral y en la Profesa, acreditan verdaderamente el apodo de Grande con que los mexicanos to distinguieron. y su cuadro de San Cristóbal en San Agustín, es un fragmento tan grande en su trazo como en la perfección del arte. Mucho de Caracci se nota en su pincel, y, quizá, tenga mayor perfección en su dibujo y en su colorido. 1 Su tío Luis y su hermano Nicolás, merecen, asimismo, el nombre de Rodriguez. Dan fe de ello el convento de San Francisco y San Lázaro. Esstos artistas fueron mexicanos.

El padre Manuel, jesuita mexicano, pintaba admirablemente con las dos manos. La Cena del Refectorio de las Padres Fornandinos es una hermosa muestra de su talento. 2

Juan Correa debió tener para pintar una facilidad tan grande cono su talento, pues ha llenado a México con sus obras. Su colorido no es de

I D. Pelegrín Clavé expresó sobre este mismo punto la siguiente opinión:

“Para conocer el mérito de ese pintor (Juan Rodriguez Juárez), es necesario ver en la iglesia de San Agustín, en la puerta del costado, los dos grandes cuadros que allí dejó y serán perenne monumeato de su gloria. El uno es un San Cristóbal colosal, trazado con vigor $e$ inteligencia: el otro tepresenta una visión de Santa Gertrudis, que está arrodillada en la parte inferior. contemplando a San Agustín que aparece arriba en gloria. Tal vez hasta su tiempo no se habia hecho en México pintura que le secara ventaja. Sin meterme en las compataciones de Beltrami, sin decir que en Rodríguez Juárez bay macho de Caracci, y que acaso le excede en el colorido y el dibujo. si creo que el nombre del primeto no acabará mientras su cuadro de Santa Gertrudis exista". (Diálogo Sobre la Pintura en México".-Por D. Bernardo Couto.-México.-1889.-Pág. 48).

2 Acerca de esta "Cena del Refectorio de los Padres Femandinos". escribe don. José Bernardo Couto:

". . del mismo siglo XVII conozca además, de otros (pintores) oscuros, algunos. que por su mérito. . nombraré." ..."El cuarto es el padre Manuel. Jesuíta. de cuya vida no he podido alcanzar noticia, a pesar de haberla buscado con diligencia. Beltrami que to coloca (ignoro sobre qué dato) en el siglo siguiente, dice que pintaba admirablemente con ambas manos y que él vió una bella muestra de su talento en un cuadro de la Cena, en el refectorio de San Fernando. Bien hace quince años que yo busco la tal Cena en aquel convento, y no doy con ella. ni hay padre de los antiguos que fa recuerde. La que allí enseñan, y está ahora en un claustro de arriba, junto a la puerta de entrada de la sala de recibir, es obra de Pedro López Calderón, ejecutada en 1728, y firmada de su mano: dé mediano mérito. Donde realmente babia una pintura del padre Manuel, era en la escalera del Colegio de S. Gregorio, que se conservaba como estruvo en tiempo de los jesuítas. Es un cuadro apaisado, formado del autor, y que representa la sacra Familia". (Diálogo Sobre la Historia de la Pintura en México".-Por D. Bernardo Conto.—Mérico._1 889 ._Págs. 43 y 44). 
los más bellos, pero su composición es grande y sublime. Sus cuadros de la sacristía de la Catedral y sus frescos de la iglesia de Santa Teresa la Antigua, con todos sus defectos, muestran a un artista célebre. Grande en todo, tuvo también gran número de discípulos, todos mexicanos y más o menos famosos, como Cabrera, José Ibarra, Antonio Aquillara, José de Crudecindo, etc., que, con otros, hicieron florecer la mitad del siglo dieciocho.

Algunas de las pinturas de Cabrera fueron llamadas Maravillas Americanas y son todas de un alto valor. La vida de Santo Domingo pintadi por él en el claustro de Santo Domingo, la Vida de San Ignacio y la Historia del Corasón del Hombre Deformado por el Pecado Mortal y Regenerado Hacia la Religión y la Virtud, pintada en el claustro de la Profesa, son dos galerías no inferiores a las del Claustro de Santa Maria Novella en Florencia y del Campo Santo de Pisa. Quizá sea atrevido afirmar que Cabrera, en esos dos claustros, vale tanto como todos los artistas que pintaron las dos grandes galerías italianas. Tiene los contornos de Coreggio, la animación de Domenichino y el patetismo de Murillo. Sus episodios como el de los Angeles, etc., son de una rara beileza. En mi opinión fué un gran pintor. Arquitecto y escultor en marlera, fué el Miguel. Angel de México.

Francisco Antonio Valleso, buen pintor de ese tiempo, ha dejado en el Colegio de San Ildefonso preciosos monumentos de su arte, principalmente en el cuadro de la muerte de San Francisco Javier.

José de Páez se muestra un artista distinguido en las pinturas del Claustro de San Fernando.

José Ibarra, contemporáneo de Cabrera y alumno como él de Correa, ha dejado a la posteridad buenos modelos en Santa Inés, Betlemitas y otros lugares.

Mariano Vázquez es el Carlin Dolce de México. Sus obras en la Academia y en otros sitios, atestiguan que fué un digno discipulo de Cabrera.

Las pinturas que se han conservado de José Alcivaz en el claustro superior del Convento de San Agustín, prueban que no fue muy inferior a su maestro Ibarra. El San Luis Gonzaga del Sagrario de la Catedral tiene un aspecto no menos notable.

Domingo Manrique fue un gran ornamentador y un buen arquitecto.

EI fin del siglo, como los dos primeros tercios, tuvo sus grandes artistas.

Joaquin Esquivel hubiera sido clásico si no hubiese descuidado tanto sus obras. En sus pinturas su genio duerme-si es que puedo expresarme de este modo-, sin ocuparse del dibujo ni de las concordancias. Prueban esto 
sus cuadros del claustro de la Merced y de la Iglesia de Loreto. Nació gran pintor, pero no tuvo paciencia para evolucionar. Sus obras muestran grandes cualidades y grandes defectos, de cualquier manera, fue un artista notable.

Juan Sáenz pintó casi todo el interior de la cúpula de la catedral, pero la muerte lo sorprendió a la mitad de su empresa. Lua obra fue terminada por Rafael Ximenes, director actual de esta Academia de Bellas Artes, que ha reemplazado dignamente al artista mexicano; pero lo que resta del pincel de éste, sirve de punto de comparación muy inoportuno para el amor propio det artista español. Creo, además, que el segundo ha trabajado sirviéndose de los estudios y proyectos del primero.

Manuel Garcia y Juan Urtado fueron grandes pintores en perspectiva y buenos arquitectos; a ellos se deben la mayor parte de los monumentos llamados Sancta Sanctorum, que resplandecen de belleza, de riqueza y de magnificencia sobre los grandes altares de las principales iglesias de México.

El siglo XVIII tuvo artistas muy distinguidos en todos los géneros, como los tres hermanos José, Mariano y Alejandro Guerrero, José Alfano, Manuel Serna, Ignacio Caestro, Rafael Gutieres. Andrés Intas, etc., todos mexicanos.

Notad, Condesa, que estos artistas, que fijan los mejores tiempos de las bellas artes en México. han llegado a su perfección, principalmente por su propio genio, no teniendo ni academias ni otros establecimientos públicos para cultivarlos o hacerlos nacer, y que stu Siglo Leonino ha terminado con el principio de una Academia fundada en 1781. Desde su fundación no volvió a haber un solo artista que se hubiese acercado a los Villalpandos, a los Rodríguez, a los Herreras, a los Correas, a Ios Cabreras, a los Ibarras, etc. ¿Y por qué? Es que, fundar Academias sin bellos modelos y sabios reglamentos, es peor que no establecer nada. Es hacer violencia al genio que inspira la naturaleza y que el gusto y el buen sentido corrigen sin instruir; es desanimar o detener el impulso natural sin cultivario; es destruir sin reedificar o reedificar mal. 1

1 Sobre esta observación de Beltrami vemos en un artículo. sin firma, que publicó "El Siglo Diez y Nueve":

"En efecto, es de notarse que desde la erección de la Academia de San Carlos, no haya vuelto a distinguirse en México ningún artista, como muchos se habian distinguido antes: $y$ esto puede atribuírse a lo que dice Beltrami, o a lo que nos parece a nosotros más cierto, a la falta de protección con que este siglo ba visto las artes, por las grandes ideas politicas que se han agitado, y que lo han hecho desentenderse absolutamente de todo aquello que no han sido ellas'".

"el discipulo necesita de buenos modelos para formarse un gusto puro, y este defecto. que era al que Beltrami atribuía los malos resultado de la Academia, permanece 
La apertura de la Academia se solemnizó con la asistencia del Virrey, de la Audiencia, etc, y se le puso bajo los auspicios de Carlos Tercero, lo cual fue muy conveniente, porque Carlos Tercero era tn rey bastante bueno: pero de allí no resultó una Acadenia, se necesitaban buenos profesores, y debió reservarse su parte al orgullo, si no nacional-puesto que se han guardado bien de dejar tomar la nacionalidad a los mexicanos, como se ha hecho an Italia con los italianos-, a lo menos popular. Se la llenó de espaniples y se ia transformó toda en española. Sus alumnos, buenos o malos, eran solamente artistas de derecho, y el genio mexicano penetró de nuevo por entero en el siglo pasado. Ahora la Academia no tiene más que un bello local, una galería pasadera y una colección de yesos muy escogidos. Ln gobierno nacional puede darle nuevo impulso, pero será necesario mucho tiempo, porque ante todo debe ocuparse de su situación política y financiera, y las bellas artes progresan lentamente. Entretanto, deberá tenerse cuidado de conservar lo que ha legado el genio de sus antiguos artistas. Hay con qué formar una de las galerías más bellas del Mundo.

He aqui, Condesa, un pequeño resumen de las bellas artes y de los artistas mexicanos. Sin ducla, está muy lejos de ser completo, ni yo mismo me atrevo a asegurar que lo esté, pero puede servir de guia a otros que tendrán más medios para hacer una historia cuidaclosa. El objeto vale la pena ciertamente, y yo deseo que se rectifiquen mis faltas. No escribo más que unas cartas y el estilo epistolar no es propio para tratar grandes materias y largos detalles. resulta demasiato resbaladizo. Cualquiera que se ocupe seriamente hará un gran servicio a esta nación, que, en este punto, como en tantos otros. ignora completamente lo que posee, lo que vale y lo que puede

aún en pie. Da tristeza y compasión entrar a la galeria de pinturas. y ver su mezquindad y abandono, al pensar que hay galerías paxtículares en México de mucho más mérito y mucho más abundantes. Una que otra copia de pintores célebres: alguno que otro original verdaderamente clásico. como el San Juan de Dios de Murillo, he aquí a lo que se reduce la galeria de pinturas de la Academia de Bellas Artes de México. ¿Por qué la iacuría se ha llevado hasta ese punto? ¿Por qué la academia con sus fondos no se ha anticipado a los particulares, baciéndose de todas esas pinturas de los grandes maestros españoles, y que ban ido a parar. unas a manos de mexicanos de gusto. y las más a podet de estranjeros que han ido a especular con ellas a Europa?" . "Pero la incuria ba ido a más: no se ve en la academia un solo caudro célebre de los pintores mexicanos que se distinguieron, no sabemos si por el desdén de los directores (hablamos de los que componen la junta directiva) a todo lo que es nacional, o por ignotancia de los progresos que la pintura llegó a hacer en México y de las grandes obras que produjo. No se ve allí ningún nombre que recuerde las glorias de las bellas artes nacionales, $y$ tal vez no se sospecha allí ni la existencia de un Cabrera, de un Juárez, y de tantos otros que merecen vivir en la memoria de los apreciadores del verdadero mérito".

("El Siglo Diez y Nueve".-México, jueves 2 de agosto de $1849 "$.-Tomo II. Núm. 214.-Págs. $131-132$. 
valer, y asi avanzará la Historia General, que todavia no ha penetrado bien en esas regiones lejanas, ocultas hasta ahora bajo el velo espeso de un política envidiosa y tiránica”.

De la obra: "Le Mexique", par J. C. Beltrami, Ex-Conseiller a une cour royale de l'ex-royaume d'Italie, Membre de la Société Médico-Botanique de Londres, et d'autres corps scientifiques et littéraires cis-et-transatlantiques; Auteur de la Découverte des Sources du Mississipi et de la Riviere Sanglante, du Pélerinage en Europe et en. Amérique, etc. Paris. 1830. (Tomo Segundo. "Onzieme Lettre. Págs. 203-211).

"EI Museo de Pintura no merece una noticia extensa, pues sólo ví en él un original de Murilio, algunas copias, y vaciados en yeso, en su mayor parte de antiguas estatuas de Grecia y Roma. Anexa a la Catedral hay una biblioteca, y algunos individuos ricos poseen medianas colecciones de libros y minerales; pero fue tan sistemático el esfuerzo del gobierno español y de los sacerdotes para mantener al pueblo mexicano en la ignorancia. que todo intento encaminado al progreso o al cultivo de las ciencias liberales tropezó con la oposición más resuelta".

De la obra: "Mexican Illustrations", founded upon facts, indicative of the present condition of Society, Manners, Religion, and Morals, among the Spanish and Native Inluabitants of Mexico: with observations upon the government and resources of the Republic of Mexico, as they appeared during part of the years 1825,1826 and 1827 . Interspersed with occasional remarks upon the climate, produce, and antiquities of the country, mode of working the mines, etc. By Mark Beaufoy (late of the coldstream gitards). I,ondres. 1828. Capítulo VI. Pág. 70.

"Sólo el artista-(Director de la Academia de San Carlos)-permaneció sereno, y como Su Excelencia (el Virrey) le predijo el éxito más brillante, movió la cabeza e hizo alusión a la tibieza del vulgo en materia de arte.

1 Charles Sealsfield, autor de "El Virrey o México en 1812 ", visitó nuestro país en 1828 . En su obra, la primera novela colonialista de que tenemos noticia, hace nna animaba pintura de la vida mexicana en las postrimerías del virreinato. Absurda en muchas de sus partes, la novela permite sin embargo al autor, exponer observaciones hechas durante su viaje. 

tivo".

- "Si, Exxcelencia-dijo-"el arte se consume en el marasmo más aflic-

- "Inter arma musae silent", observó el Arzobispo (de México).

- “i Perdón, Monseñor!-replicó respetuosamente el artista-el mal es más profundo. No solamente nuestra Academia de las Bellas Artes ha visto huir a sus alumnos, sino que la nación entera parece obedecer a otras aspiraciones aún vagas e indefinibles".

- "Vuestra observación es tan justa como profunda-dijo el cotonel-. No obstante, este fenómeno no es peculiar a México, se praduce en el mundo entero. La indiferencia por las bellas artes se ha vuelto general. He aquí el drama: el arte ya no sabe conmover a las masas".

- “ ¿No serán los artistas los responsables?-, insinuó doña Isabel.

- "Mil exçusas-replicó el coronel- Los artistas no han cambiado, pero ellos viven de entusiasmo; en nuestra época, enferma de transformación social, el entusiasmo tiende a desaparecer. El edificio de nuestras antiguas instituciones amenaza ruina en muchos puntos. Grandes y pequeños, todos tienen conciencia de eso, y el pueblo no entiende de dejarse desviar de su marcha ascensional por los restos de un pasado odioso, por más bellos y atractivos que puedan parecer todavía".

De la obra: "Le Vice-Roi ou I,e Mexique en 1812", Por Chatles Sealsfield. (Se ha utilizado, a falta de la edición alemana, la traducción francesa de Custave Revoilliod. 'Génova-Paris. 1888. Tomo II. Cap. XXXVI. Págs. 99 y 100).

Abril de 1828

"La Acadenia de las Bellas Artes de México tiene una colección de vaciados en yeso. griegos y romanos, algunos cuadros de mucho menos valor, pocos modelos, etc. Cuando yo visité éste instituto, me pareció muy descuidado, porque la revolución hizo desaparecer los amplios fondos que antes le proporcionaban una renta anual de 44,600 pesos. El estado de la colección es muy distinto al que tenía, por ejempio, cuando la vió Humboldt, hace 20 años".

De la obra: "Aufenthalt und Reisen in.Mexico in den Jahren 1825-1834". (Bemerkungen über Land, Produkte, Leben und Sitten der Finwohner und Beobachtungen aus dem Gebiete der Mineralogie, Geognosie, Berbaukunde, Meteorologie, Geographie, etc.) Von Joseph Burkart. Stuttgart. E. Sclwweizerbart's Verlagshandlung. 1836. Tomo I. Págs. 263-264. 
"Entre otros signos de la debilidad del gobierno actual, no debe pasarse por alto el olvido y la decadencia de muchas instituciones públicas.

"I.a importancia que para las rentas del país tiene la Casa de Moneda, hace que su mantenimiento sea objeto de atención por parte del Estado, pero la Universidad, el Museo, la Biblioteca Pública, la espléndida "Minería" o Escuela de Minas, muchos de los beneméritos hospitales fundados por los espan̄oles y la Academia de Artes, estaban en la época de nuestra visita en un olvido vergonzoso para el Gobierno y para el pueblo. El Jardín Botánico, que ocupa un patio interior del Palacio, es sostenido también indiferentemente bajo la vigilancia de un viejo molesto, de un empleado que le vende a usted un paquete de semillas del jardín, de las más vulgares, y le cobra por él cincuenta pesos con la mayor tranquilidad.

"Pero entrar en los detalles de estos asuntos equivaldria a escribir un libro en vez de una carta".

De la obra: "The Rambler in Merico". (MDCCCXXXIV). By Charles Joseph Latrobe. Londres. 1836. Carta VI. (Págs. 167-168).

“. . la Academia de las Nobles Artes, que arrojó tanta luz a México a fines del siglo pasado. Esste establecimientoto tenía 125,000 francos de renta, de los cuales, 60,000 eran ministrados por el gobierno, 50,000 por el cuerpo de mineros mexicanos, 15 por el Consulado (reunión de los más ricos negociantes de la capital). En aquella época ejerció esta institución la más grande influencia sobre el gusto de la nación, en las artes y en los procluctos industriales. Es a esta Academia a la que se deben, según $M$. de Humboldt, las casas suntuosas y los palacios elegantes que encontramos ahora en México y en Guanajuato. En sus grandes salas, bien iluminadas, se reunían todas las tardes centenares de jóvenes que venian a dibujar, unos copiando de diseños, otros del modelo vivo. No había entre ellos distinción de color ni de origen, se veía al indio al lado del blanco, el hijo del jornalero al lado del hijo de un gentil-hombre. Es necesario decir ahora que este establecimiento no está ya ni próspéro ni floreciente. Las guerras y las revoluciones interiores han expulsado las artes de este asilo y de México entero. Apenas si se encuentran hoy día algunos pintamonas que copian cuadros para las igle-: 
sias o ensayan hacer retratos. En México no se advierten en parte alguna trazas de esculturas en mármol; pero las esculturas de madera se han multiplicado mucho, cada casa tiene una Madona pintada y casi siempre vestida magnificamente. I os indios son notables en los trabajos en cera".

De la obra: "Voyage Pittoresque Dans Les Deux Anćriques". Publié sous la direction de M. Alcide D’Orbigny. París. 1836. Chapitre XI.IV. Pág. 425.

\section{Abril 3....1840}

"Visitamos la Academia de Pintura y de Escultura, llamada Academia de Bellas Artes, cuya descripción, desgraciaclamente, leí en Humboldt en mis forzados y prolongados estudios a bordo del "Jasón". 1 Ell ilustre viajero declara que, en su concepto, ella habia ejercido el más favorable influjo en la formación del gusto nacional, y su descripción la recordaba yo perfectamente. Dicenos que todas las noches, en estas espaciosas salas, iluminadas con lánparas de Argand, se reunian centenares de jóvenes, de los que algunos dibujaban copiando modelos de yeso o bien del natural, otros copiaban modelos de muebles, candelabros y demás ornamentos de bronce; cuéntanos que allí se reunian y mezclaban todas las clases, colores y razas, el indio junto al muchaco blanco y el hijo del más pobre menestral unido al del más rico de los señores; y nos refiere que la enseñanza exa gratuita y no linitada sóln a los paisajes y figuras, porque uno de los principales propósitos de la Acarlemia consistía en propagar entre los artistas un gusto general por la elegancia y belleza de la forma y clar vida a la industria nacional. El Rey de España envió modelos de yeso por valor de cuarenta mil duros, y como en la Acadenua poseen varias estatuas colosales de basaito y de pórfido, esculpidas con jeroglificos aztecas, habría sido cosa curiosa. segín lo hace notar el mismo ilustre viajero, reunir todos estos monumentos en el patio de la Academia, y comparar los restos de la escultura mexicana, monumentos de un pueblo semibárbaro, con las grandes creaciones de Grecia y Roma.

"Pero guardaos de visitar la Academia llevando en la mente estas ilusiones y remembranzas...

1 Bergantín de guerra de la escuadra española en el que los Marqueaes Calderón de 1a Barca hicieron el viaje de La Habana a Veracruz. (24 de noviembre o 18 de diciembre de 1839). 
"No cabe dudar que a los progresos realizados en esta misma Acadenia se debe el sencillo y noble gusto que distingue los edificios mexicanos, la perfección en el corte y labrado de la piedra y lo casto de los ornamentos de chapiteles y relieves. Los restos de esos bellos aunque mutilados modelos de yeso; los espléndidos grabados que todavia existen, bastarian para demostrar la probabilidad del anterior aserto; pero el actual desorden, el estado de abandono en que se encuentra el edificio, la ausencia de esas excelentes clases de escultura y pintura, y sobre todo, la decadencia en que ahora se encuentran las bellas artes en México, forman parte de las tristes pruebas, si es que algunas se necesitan, de los lamentables efectos que producen años de guerra civil y de inestabilidad en el gobierno..."

De la obra: "I a Vida en México". Por Marquesa Calderón cle la Batca. Tomo I.-Carta Décimatercera.- ( Se ha utilizado la traducción española que del original en inglés hizo don Enrique Martínez Sobral, publicada en México por la l.jbreria Bouret en 1920.--Págs. 193-195).

1842...."Academia de Axteg"

"Dejemos el examen de los vicios y de la inmoralidad en México. para tratar algo más agradable.

"La descripción que hizo el Barón de Humboldt de la Academia de Bellas artes, habia excitado mucho mi curiosidad; pero grande fue mi decepción, comparando lo que él narra y viendo el estado miserable que loy guarda. Ha corrido igual suerte que la Universidad, el Museo, la Fscuela de Minería y otras instituciones públicas. Los salones están vacíos. La muchedumbre que, según el Barón, recibía instrucción de los profesores y diseñaba de la espléndida colección de modelos antiguos, ha desaparecido. En un taller desarreglado que está en un rincón oscuro del edificio, hay un artista que hace retratos poco naturales de militares ridículos, cubiertos de galones dorados, de bordados y de cruces, en un estilo tan chocante como sus ademanes.

"Es de esperarse que con la "regeneración de la República", se impulse esta rama agradable de la ciencia, y se sujete a disciplina el talento notablemente sutil e imitativo de los naturales, y no se impida ya a los mexicanos colocarse en un lugar distinguido del campo de las bellas artes.

*E1 Gobierno español dotaba a la institución con un subsidio anual de cerca de veinticinco mil dólares, y gastó cuarenta mil en transladar a México, a través de caminos mortañosos y veredas, una bella colección de va- 
ciados de las estatuas más famosas y grupos escultóricos de la antigüedad. Todos ellos-me alegra decirlo-están en buen estado y adornan todavía los desiertos salones de la Academia olvidada.

"Pregunté por las pinturas de los antiguos académicos, y me enseñaron algunas de feos colores y peor traza.

"Pregunté por los dibujos, y la respuesta fué que no había sino unos cuantos diseños colgados en las paredes, con fechas muy antiguas. Pude descubrir entre ellos, sin embargo, un dibujo a tinta, hecho gor uno de los alumnos, que si hubiese sido ejecutado en cobre, hubiera colocado a su autor en primera fila entre los grabadores de su tiempo".

De la obra: "México As It Was And As It Is".--By Brantz Mayer, Secretary of the U. S. Legation to that country in 1841 and 1842. - New York. 1844. Carta XXVI. Págs. 271-272.

"Humboldt, que visitó México en 1804, dice que las instituciones científicas de la ciudad eran en ese tiempo iguales, si no superiores a las de losEstados Unidos. A mi me parece que la Güera Rodríguez, la hermosa dama que tanto le agradó, no fué lo únjco que vió en México color de rosa. La única institución de algún carácter en la ciudad, es "Minería" (el Colegio. de Minas, como su nombre indica). El edificio es un conjunto magnífico.

"La Academia de Bellas Artes es, creo yo, muy inferior al Colegio de Minería. Hay muy buenos vaciados en yeso de los trabajos más célebres dela estatuaria y numerosas pinturas mily inferiores. En toclo México no hay un retratista siquiera aceptable.

"Parecen haber tomado la absurda resolución de no avanzar. con la. época en que viven en cosa alguna, y aunque se debía suponer que en lo que. atañe a la acuñación de los metales preciosos-en los que su país abunda y con los que contribuye tanto a la acuñación de monerla en el mundo-podría encontrarse una excepción, no sucede asi. El proceso es, en casi todos los casos, el del tiempo de la conquista. En la Casa de Moneda de México, queindudablemente ha acuñado mayor cantidad de metales preciosos que ninguna otra en el mundo, no hay siquiera una máquina de vapor".

De la obra: "Recollections of Mexico". By Waddy Thompson, Hsq.Late Envoy Extraordinary and Minister Plenipotenciary of the United States at Mexico.-New York. 1846. Cap. XV. Págs. 147-148. 
"La Academia de las Bellas Artes, instituto que tenía antes material tan excelente-modelos y grabados en cobre que costaron al Gobierno español más de 80,000 F1.C.M.-que ni en Europa había mejor escuela para dibujantes y escultores, nos muestra la decadencia del arte en México. Aqui, donde pobres y ricos, blancos y aborigenes se educaban juntos y tanto noble y hermoso se producía, no hay escuela de dibujo ni de escultura; los preciosos modelos de yeso están maltratados y las colecciones, en el mismo estado de abandono que todo el edificio.

"Probablemente se espera en vano un nuevo florecimiento de este instituto en el estado actual de este país".

De la obra: "Reisen in Mexiko In Den Jahren 1845-1848". Por Cart Bartholomaeus Heller.-Leipzig. 1853. Chapitel X. Págs. 147-148.

Hay en la ciudad dos motivos de atracción a los que aún no he presentado mis respetos: son la Academia de (Bellas) Artes y la Escuela de Minas o "Minería". La primera, me han dicho, está en decadencia aún cuando en un tiempo estuvo bien dotada y altamente estimada ; la última, un magnífico edificio, ha sido ocupada, debo decir, por el valiente regimiento de dragones. Es una escuela de matemáticas, mineralogía y creo que en general de filosofía natural. pero aún cuando está en actividad no se la considera floreciente".

De la obra: "El Puchero" or A Mixed Dish From Mexico, Embracing General Scott's Campaign with Sketches of Military Life, in field and Camp, of the Character of the Country, Manners and Ways of the People, etc.-By Richard M'Sherry, M. D., U. S. N.-(Late acting Surgeon of Regiment of. Marines).-Filadelfia.-1850.--Letter XLIII.-Pág. 188. 